\title{
Sex differences in coronary plaque changes assessed by serial computed tomography angiography
}

\author{
Mohammed El Mahdiui ${ }^{1}$ - Jeff M. Smit ${ }^{1}$ - Alexander R. van Rosendael ${ }^{1}$. Danilo Neglia ${ }^{2}$. Juhani Knuuti ${ }^{3}$. \\ Antti Saraste $^{3}$ - Ronny R. Buechel ${ }^{4} \cdot$ Anna Teresinska $^{5} \cdot$ Maria N. Pizzi $^{6} \cdot$ Albert Roque $^{7} \cdot$ Massimo Magnacca $^{8}$. \\ Bart J. Mertens ${ }^{9} \cdot$ Chiara Caselli $^{10}$. Silvia Rocchiccioli ${ }^{10}$. Oberdan Parodi ${ }^{10,11}$. Gualtiero Pelosi ${ }^{10}$. Arthur J. Scholte $^{1}$
}

Received: 12 November 2020 / Accepted: 22 February 2021 / Published online: 10 March 2021

(c) The Author(s) 2021

\begin{abstract}
Long-term data on sex-differences in coronary plaque changes over time is lacking in a low-to-intermediate risk population of stable coronary artery disease (CAD). The aim of this study was to evaluate the role of sex on long-term plaque progression and evolution of plaque composition. Furthermore, the influence of menopause on plaque progression and composition was also evaluated. Patients that underwent a coronary computed tomography angiography (CTA) were prospectively included to undergo a follow-up coronary CTA. Total and compositional plaque volumes were normalized using the vessel volume to calculate a percentage atheroma volume (PAV). To investigate the influence of menopause on plaque progression, patients were divided into two groups, under and over 55 years of age. In total, 211 patients were included in this analysis, $146(69 \%)$ men. The mean interscan period between baseline and follow-up coronary CTA was $6.2 \pm 1.4$ years. Women were older, had higher HDL levels and presented more often with atypical chest pain. Men had 434 plaque sites and women 156. On a per-lesion analysis, women had less fibro-fatty PAV compared to men $(\beta-1.3 \pm 0.4 \% ; \mathrm{p}<0.001)$, with no other significant differences. When stratifying patients by 55 years age threshold, fibro-fatty PAV remained higher in men in both age groups $(p<0.05)$ whilst women younger than 55 years demonstrated more regression of fibrous $(\beta-0.8 \pm 0.3 \%$ per year; $p=0.002)$ and non-calcified PAV ( $\beta-0.7 \pm 0.3 \%$ per year; $p=0.027$ ). In a low-to-intermediate risk population of stable CAD patients, no significant sex differences in total PAV increase over time were observed. Fibro-fatty PAV was lower in women at any age and women under 55 years demonstrated significantly greater reduction in fibrous and non-calcified PAV over time compared to age-matched men. (ClinicalTrials.gov number, NCT04448691.)
\end{abstract}

Keywords Coronary artery disease $\cdot$ Coronary computed tomography angiography $\cdot$ Sex $\cdot$ Menopause

\section{Abbreviations}

ACS acute coronary syndrome

CAD coronary artery disease

CTA computed tomography angiography
HRT hormone replacement therapy

HU Hounsfield units

IVUS-VH intravascular ultrasound virtual histology

PAV percentage atheroma volume
Arthur J. Scholte

A.J.H.A.Scholte@lumc.nl

1 Department of Cardiology, Leiden University Medical Center, Albinusdreef 2, 2300 RC Leiden, The Netherlands

2 Fondazione Toscana Gabriele Monasterio, Viale Giuseppe Moruzzi 1 56124, Pisa, Italy

3 Heart Center and PET Centre, Turku University Hospital and University of Turku, Turku, Finland

4 Department of Nuclear Medicine, Cardiac Imaging, University Hospital and University of Zurich, Zurich, Switzerland

5 National Institute of Cardiology, Warsaw, Poland
6 Department of Cardiology, Hospital Universitari Vall D'Hebron, Barcelona, Spain

7 Department of Radiology, Hospital Universitari Vall D'Hebron, Barcelona, Spain

8 ASL12 U.O.C. Cardiologia, Viareggio, Italy

9 Department of Medical Statistics, Leiden University Medical Center, Leiden, The Netherlands

10 Institute of Clinical Physiology CNR, Viale Giuseppe Moruzzi 1 56124, Pisa, Italy

11 Institute of Information Science and Technologies CNR, Pisa, Italy 


\section{Introduction}

Several studies have highlighted distinct sex-related differences for coronary artery disease (CAD). Women tend to be older when presenting with CAD [1], have lower rates of obstructive disease [2] but higher risk of major adverse cardiac events compared to men [2-5]. This discrepancy might arise from differences in plaque characteristics between men and women [6]. Postmortem histology studies reported plaque morphological differences between men and women [7-10]. However, in vivo intravascular studies have shown conflicting data regarding plaque burden and morphology between men and women [11-22]. These invasive studies were though performed in patients with an acute coronary syndrome (ACS), did not evaluate the plaques in the whole coronary tree or did not prospectively investigate sex differences in the natural plaque evolution over a long follow-up period. Coronary computed tomography angiography (CTA) allows for a fast and non-invasive assessment of coronary plaque burden and characterization of plaque composition comparable with intravascular ultrasound virtual histology (IVUS-VH) [23]. The aim of the current study was to evaluate the influence of sex on long-term in vivo plaque progression and evolution of plaque composition in a low-to-intermediate risk population in stable clinical conditions. Furthermore, the role of menopause on plaque progression and composition was also evaluated.

\section{Materials and methods}

\section{Study design}

The SMARTool (Simulation Modeling of coronary ARTery disease: a tool for clinical decision support, Horizon 2020) project, is a prospective, international, multicenter study with the aim of integrating clinical, molecular, cellular and imaging data to provide a patient-specific risk stratification model exploitable for clinical decision support in stable CAD management [24, 25]. Patients who had undergone a coronary CTA at baseline for suspected CAD were prospectively included and subsequently underwent a follow-up coronary CTA. Patients with stable CAD without a history of myocardial infarction, heart failure or surgical procedures related to heart diseases were included. The complete inclusion and exclusion criteria are provided in the supplementary material.

\section{Study population}

Patients who had undergone clinically indicated coronary CTA in the period 2009-2012 or were part of the EVINCI (FP7-222,915) or the ARTreat (FP7-224,297) clinical studies were included. The Diamond-Forrester model was used to estimate the pretest probability of CAD [26]. Inclusion and exclusion criteria have been previously [25]. Data on cardiovascular risk factors and medical therapy were prospectively collected at baseline and follow-up. Statin intensity was classified according to the American College of Cardiology and American Heart Association guidelines [27]. In total, 275 patients from 5 European countries (Finland, Italy, Poland, Spain and Switzerland) were recruited in 7 centers. Of the 263 patients who underwent a follow-up coronary CTA, 52 patients were excluded because of uninterpretable coronary CTA for visual $(n=5)$ or quantitative CTA analysis $(\mathrm{n}=11)$ or absence of coronary plaques at follow-up $(n=36)$. Thus, 211 patients were finally included in the present analysis (Fig. 1).

\section{Coronary CTA analysis protocol}

The coronary CTA protocol has been described previously [25]. In brief, anonymized coronary CTA data were transferred to a core laboratory (Leiden University Medical

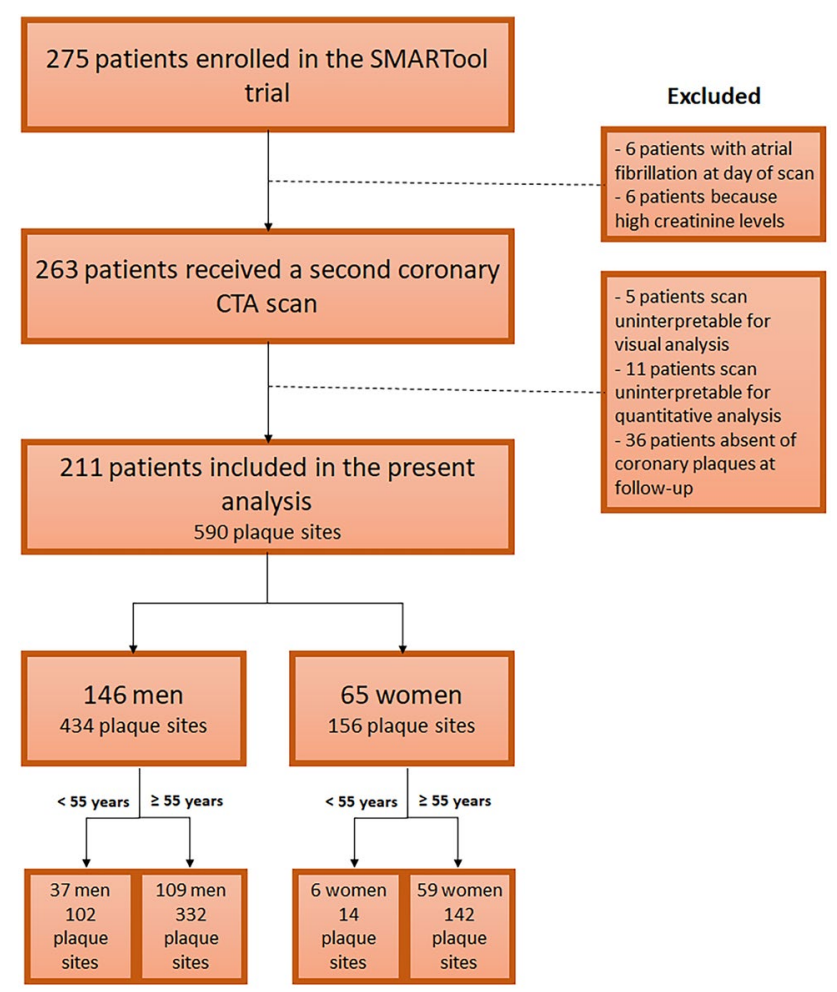

Fig. 1 Flow diagram of the study population 
Center) for visual and quantitative analysis (supplementary material) and researchers were blinded to patients clinical data. Quantitative analysis was performed on visually identified plaques using a dedicated software package (QAngio CT Research Edition version 3.1.2.0, Medis Medical Imaging Systems, Leiden, the Netherlands). The software automatically detects the centerline, lumen and the vessel wall and allows the user for manual adjustment if needed $[23,28]$. The baseline and follow-up coronary CTA were analyzed side-by-side and lesions were identified using anatomical markers. Several parameters were derived from the quantitative analysis: percentage diameters stenosis, lesion length, remodeling index, total vessel volume, total plaque volume and plaque composition volumes. Plaque composition volumes were determined using predefined Hounsfield units (HU) cutoff values: $>350 \mathrm{HU}$ for calcified plaque and -30 to $350 \mathrm{HU}$ for non-calcified plaque. Non-calcified plaque was further classified in necrotic core plaque (-30 to $75 \mathrm{HU})$, fibro-fatty plaque (76 to $130 \mathrm{HU}$ ) and fibrous plaque (131 to $350 \mathrm{HU})$. Total plaque volume and plaque composition volumes were normalized for the vessel volume and the percentage atheroma volume (PAV) calculated as follows: (plaque volume/ total vessel volume) $\times 100 \%$ and reported as a percentage. The inter- and intra-observer variability have been described previously [28-30].

\section{Statistical analysis}

Continuous variables are expressed as mean \pm standard deviation (SD) if normally distributed and median and interquartile range (IQR) if non-normally distributed. Normality was assessed using histograms and Q-Q plots. Categorical variables are presented as frequencies and percentages and compared using the Chi square test or the Fisher's exact test. Normally distributed continuous variables were compared using the Student's $t$-test and the Mann-Whitney $U$-test if not normally distributed. Quantitative analysis parameters were compared on a per-lesion basis. Analysis of annual rate of lesion progression was performed using linear mixed models (LMM) to correct for per lesion and per patient factors. Fixed effects in the models included sex, interscan period and the interaction between sex and interscan period. In addition, the LMM was adjusted for age, hypertension, diabetes mellitus, smoking, family history of CAD, obesity, LDL and HDL at baseline. Random effects included intercept and an unstructured covariance was used to account for within-patient and within-plaque correlation over time. A sub-analysis was performed in patients aged under and over 55 years at baseline coronary CTA scan to assess the influence of menopause on plaque progression in women compared to men. The models provide a test for systematic between-group difference across time, as well as a test for between-group differences in the trend. The estimated difference ( $\beta$ ) of women compared to men and the interaction are presented with standard error (SE), 95\% confidence interval (CI) and p-values. Statistical analyses were performed using SPSS version 25.0 (SPSS, Armonk, $\mathrm{NY}$ ) and a two-sided p-value $<0.05$ was considered statistically significant.

\section{Results}

\section{Baseline patient characteristics}

Of the 211 patients included in the present analysis, 146 (69\%) were men and $65(31 \%)$ were women. Women were generally older, had higher HDL levels and presented more often with atypical chest pain. The mean interscan period between baseline and follow-up coronary CTAs was $6.2 \pm 1.4$ years (minimum 1.9- maximum 11.3). Baseline patient characteristics are shown in Table 1 . When stratifying the population according to age groups, $43(20 \%)$ were under 55 years at the time of baseline coronary CTA scan and $168(80 \%)$ were 55 years or older.

\section{Baseline plaque characteristics and changes of total and compositional PAV}

A total of 590 plaques were identified, 434 (74\%) plaques were found in men and $156(26 \%)$ in women. Baseline plaque characteristics are shown in Table 2 . At baseline men had higher degree of stenosis $(\mathrm{p}<0.05)$. Men also had higher absolute volumes of fibro-fatty and necrotic core $(p<0.05)$, but after correction for vessel volume only fibro-fatty PAV remained higher in men $(\mathrm{p}<0.001)$. Table 3 summarizes the differences in plaque changes between men and women. Total PAV increased $0.42 \%$ / per lesion/ per year and $0.34 \%$ / per lesion/ per year, in men and women respectively, no difference in the progression was observed $(\beta-0.1 \pm 0.1$ (95\% CI -0.2 to 0.1$) \%$ per year; $p=0.320$ ). Similarly, no sex differences in compositional changes were observed, although women had less fibro-fatty PAV per-lesion compared to men during follow-up ( $\beta-1.3 \pm 0.4$ (95\% CI -2.0 to -0.6$)$ $\% ; \mathrm{p}<0.001)$, despite no difference in the rate of plaque progression compared to men $(\mathrm{p}=0.416)$ (Fig. 2). Examples of quantitative coronary plaque analysis are demonstrated in Fig. 3.

\section{Sex differences and the role of menopause on plaque progression}

Table 4 summarizes the differences in plaque progression between men and women stratified according to age $(<55$ vs $\geq 55$ years). Women had less fibro-fatty PAV in both age groups ( $<55$ vs $\geq 55$ years) compared to men $(p<0.05)$. 
Table 1 Patient characteristics

\begin{tabular}{|c|c|c|c|c|}
\hline Variables & $\begin{array}{l}\text { Total } \\
(\mathrm{n}=211)\end{array}$ & $\begin{array}{l}\text { Men } \\
(n=146)\end{array}$ & $\begin{array}{l}\text { Women } \\
(n=65)\end{array}$ & $\mathrm{p}$-value \\
\hline \multicolumn{5}{|l|}{ Clinical } \\
\hline Age, years & $62 \pm 8$ & $61 \pm 8$ & $64 \pm 7$ & 0.001 \\
\hline Body mass index, $\mathrm{kg} / \mathrm{m}^{2}$ & $27.6 \pm 3.8$ & $27.6 \pm 3.4$ & $27.5 \pm 4.5$ & 0.835 \\
\hline Family history of CAD & $96(46)$ & $59(40)$ & $37(57)$ & 0.049 \\
\hline Current smoker & $33(16)$ & $25(17)$ & $8(12)$ & 0.306 \\
\hline Diabetes mellitus & $41(19)$ & $25(17)$ & $16(25)$ & 0.266 \\
\hline Dyslipidemia & $138(65)$ & $91(62)$ & $47(72)$ & 0.305 \\
\hline Hypertension & $136(65)$ & $90(62)$ & $46(71)$ & 0.370 \\
\hline \multicolumn{5}{|l|}{ Chest pain } \\
\hline Typical & $47(22)$ & $34(23)$ & $13(20)$ & 0.310 \\
\hline Atypical & $96(46)$ & $56(38)$ & $40(62)$ & 0.017 \\
\hline Non-anginal & $1(1)$ & $1(1)$ & $0(0)$ & 1.000 \\
\hline \multicolumn{5}{|l|}{ Medication } \\
\hline ACE-inhibitors/ARB's & $96(46)$ & $64(44)$ & $32(49)$ & 0.839 \\
\hline Aspirin & $133(63)$ & $90(62)$ & $43(66)$ & 0.891 \\
\hline Beta-blockers & $86(41)$ & $55(38)$ & $31(48)$ & 0.366 \\
\hline Diuretics & $32(15)$ & $13(9)$ & $19(29)$ & $<0.001$ \\
\hline \multicolumn{5}{|l|}{ Statin therapy } \\
\hline Statins at baseline & $112(53)$ & $74(51)$ & $38(59)$ & 0.296 \\
\hline High-intensity & $7(6)$ & $4(5)$ & $3(8)$ & 0.687 \\
\hline Low-/Moderate-intensity & $34(30)$ & $25(34)$ & $9(24)$ & 0.271 \\
\hline Statins at follow-up & $145(69)$ & $105(72)$ & $40(62)$ & 0.133 \\
\hline High-intensity & 27 (19) & $19(19)$ & $8(20)$ & 0.792 \\
\hline Low-/Moderate-intensity & $110(76)$ & $78(77)$ & $32(80)$ & 0.472 \\
\hline \multicolumn{5}{|l|}{ Biochemical } \\
\hline Creatinine, $\mathrm{mg} / \mathrm{dl}$ & $0.873 \pm 0.197$ & $0.943 \pm 0.174$ & $0.734 \pm 0.166$ & $<0.001$ \\
\hline Glucose, mg/dl & $109.51 \pm 26.63$ & $110.55 \pm 26.80$ & $107.42 \pm 26.38$ & 0.458 \\
\hline Triglycerides, mg/dL & $121.93 \pm 62.51$ & $126.92 \pm 65.04$ & $111.66 \pm 56.13$ & 0.125 \\
\hline Total Cholesterol, mg/dL & $185.52 \pm 48.32$ & $182.55 \pm 48.29$ & $192.23 \pm 48.10$ & 0.190 \\
\hline $\mathrm{LDL}, \mathrm{mg} / \mathrm{dL}$ & $110.28 \pm 41.24$ & $108.35 \pm 41.42$ & $114.65 \pm 40.84$ & 0.318 \\
\hline HDL, mg/dL & $51.33 \pm 14.87$ & $49.28 \pm 14.53$ & $55.97 \pm 14.69$ & 0.003 \\
\hline
\end{tabular}

Bold indicates statistical signifcance of $\mathrm{p}$ value $<0.05$

Patient characteristics are at baseline unless otherwise indicated. Values are presented as mean \pm standard deviation or $\mathrm{n}(\%)$

$A C E$ angiotensin-converting enzyme, $A R B$ angiotensin-II-receptor blocker, $C A D$ coronary artery disease, $H D L$ high-density lipoprotein, $L D L$ low-density lipoprotein

Women younger than 55 years showed more regression of fibrous PAV ( $\beta-0.8 \pm 0.3(95 \%$ CI -1.3 to -0.3$) \%$ per year; $\mathrm{p}=0.002)$ and non-calcified PAV $(\beta-0.7 \pm 0.3(95 \% \mathrm{CI}-1.4$ to -0.1$) \%$ per year; $p=0.027)$, compared to men. These differences were absent in the age group $\geq 55$ years old (Fig. 4).

\section{Discussion}

In this prospective and multicenter study of serial coronary CTA we demonstrated that fibro-fatty PAV was higher in men compared to women at any age. During long-term follow-up no sex differences were detected in the change of total or compositional PAV on a per-lesion analysis after correction for multiple cardiovascular risk factors. However, when stratifying patients according to age groups $(<55$ vs $\geq 55$ years), coronary plaques in women younger than 55 years demonstrated more pronounced reduction of fibrous and non-calcified PAV compared to age-matched men. These results provide further insight in the understanding of the role of sex on long-term evolution of plaque morphology in stable CAD.

Similar to previous studies, we found that women had fewer lesions compared to men $[8,15]$. However, the total PAV per-lesion at baseline was comparable for men and women, which was also demonstrated in several other 
Table 2 Plaque characteristics at baseline

\begin{tabular}{|c|c|c|c|c|}
\hline Variables & $\begin{array}{l}\text { Total } \\
(\mathrm{n}=590)\end{array}$ & $\begin{array}{l}\text { Men } \\
(n=434)\end{array}$ & $\begin{array}{l}\text { Women } \\
(\mathrm{n}=156)\end{array}$ & p-value \\
\hline Lesion length, mm & $13.3(6.5-30.5)$ & $13.4(6.6-31.6)$ & $13.1(6.1-24.9)$ & 0.196 \\
\hline Diameter stenosis, $\%$ & $23.8(14.5-32.8)$ & $24.6(14.9-33.5)$ & $21.5(13.3-30.8)$ & 0.044 \\
\hline Remodeling index & $0.85 \pm 0.16$ & $0.85 \pm 0.16$ & $0.85 \pm 0.15$ & 0.973 \\
\hline Total vessel volume, $\mathrm{mm}^{3}$ & $247.7(116.2-528.1)$ & $252.1(123.5-550.0)$ & $229.6(101.3-426.4)$ & 0.072 \\
\hline Total plaque volume, $\mathrm{mm}^{3}$ & $141.0(67.5-302.8)$ & $143.3(70.6-322.3)$ & $133.2(60.0-239.4)$ & 0.094 \\
\hline Calcified plaque volume, $\mathrm{mm}^{3}$ & $7.7(1.7-23.0)$ & $7.3(1.7-22.4)$ & $8.5(1.8-23.3)$ & 0.659 \\
\hline Non-calcified plaque volume, $\mathrm{mm}^{3}$ & $123.3(57.3-269.7)$ & $128.0(58.7-284.1)$ & $114.7(52.4-205.7)$ & 0.082 \\
\hline Fibrous plaque volume, $\mathrm{mm}^{3}$ & $53.6(24.7-113.4)$ & $54.3(24.7-119.1)$ & $50.9(23.8-105.6)$ & 0.383 \\
\hline Fibro-fatty plaque volume, $\mathrm{mm}^{3}$ & $27.8(12.9-63.1)$ & $29.3(13.2-68.9)$ & $24.5(11.0-49.8)$ & 0.009 \\
\hline Necrotic core plaque volume, $\mathrm{mm}^{3}$ & $34.4(15.1-75.4)$ & $37.3(16.0-82.3)$ & $30.2(12.5-62.8)$ & 0.032 \\
\hline Total PAV, $\%$ & $57.9 \pm 7.8$ & $57.7 \pm 7.7$ & $58.3 \pm 7.9$ & 0.453 \\
\hline Calcified PAV, $\%$ & $3.4(0.8-7.7)$ & $3.2(0.8-7.5)$ & $4.1(1.4-8.3)$ & 0.062 \\
\hline Non-calcified PAV, $\%$ & $50.6 \pm 8.6$ & $50.8 \pm 9.0$ & $50.0 \pm 7.4$ & 0.304 \\
\hline Fibrous PAV, \% & $23.0 \pm 8.1$ & $22.7 \pm 8.1$ & $23.8 \pm 8.2$ & 0.167 \\
\hline Fibro-fatty PAV, $\%$ & $12.0 \pm 3.4$ & $12.4 \pm 3.5$ & $10.9 \pm 2.8$ & $<0.001$ \\
\hline Necrotic core PAV, \% & $15.6 \pm 6.6$ & $15.7 \pm 6.5$ & $15.3 \pm 6.9$ & 0.492 \\
\hline
\end{tabular}

Bold indicates statistical signifcance of $\mathrm{p}$ value $<0.05$

Values are presented as mean \pm standard deviation or median (interquartile range)

$P A V$ percentage atheroma volume

studies using IVUS [11, 14, 15, 31]. In a sub analysis of the PROSPECT (Providing Regional Observations to Study Predictors of Events in the Coronary Tree) trial, women had fewer lesions and fewer diseased vessels than men, yet comparable plaque burden on a per-lesion analysis. More importantly, we did not find sex differences in the progression of total PAV during long-term follow-up. Few studies have investigated the influence of sex on quantitatively assessed plaque progression. In a population of 727 men and 251 women, Nicholls et al. also demonstrated no sex differences in the progression of total PAV using IVUS during a follow-up of 18-24 months [12]. Plaque compositional differences between men and women were first reported from limited postmortem studies in patients with advanced CAD and demonstrated coronary plaques in women, especially young women, contained less dense fibrous tissue compared to men $[7,8]$. More recently, IVUS-VH studies in patients with ACS demonstrated women tend to have lower fibrous tissue compared to men $[14,15]$. This is in agreement with our findings of a greater reduction of fibrous PAV in women younger than 55 years compared to age-matched men. Absolute values of fibro-fatty PAV were higher in men compared to women in both age groups, and at both CTA scan time points, as previously described[15] but its change in time did not differ between men and women. Non-calcified PAV regressed more in women younger than 55 years than in younger men, without any difference in subjects of 55 years or older. Given the known association between non-calcified plaques with ischemia and ACS, these findings might partially explain the lower risk of symptomatic CAD in young women [32-34].

Cardiovascular diseases are increased in women after menopause and the loss of protective female sex hormones has been suggested to play an important role [35]. Sex hormones demonstrate a wide range of effects on endothelial cells, vascular tone, lipids, coagulation and cardiomyocytes [35]. Consequently, several large randomized trials were conducted to investigate hormone replacement therapy (HRT) following menopause for reducing risk of cardiovascular disease. Although the Women's Health Initiative trials demonstrated no benefit of HRT initiated late after menopause on cardiovascular events $[36,37]$, other trials demonstrated that timely starting of HRT was associated with lower progression of atherosclerosis, but did not find evidence for an effect on coronary atherosclerosis progression [38-41]. Our findings of a similar progression of total PAV between men and women in both age groups, but differences in compositional changes between men and women younger than 55 years but not in those of 55 years or older is a new insight. Although previous trials have not demonstrate an effect of HRT on total coronary atherosclerosis changes, our findings suggest coronary plaques should be evaluated for compositional changes following HRT. HRT might potentially positively influence plaque compositional changes. 
Table 3 Plaque morphological and compositional changes on a perlesion analysis shown for women compared to men

\begin{tabular}{|c|c|c|}
\hline Variables & $\begin{array}{l}\text { Total }(n=590) \beta \pm \operatorname{SE}(95 \% \\
\text { CI) }\end{array}$ & $\mathrm{p}$-value \\
\hline \multicolumn{3}{|l|}{ Lesion length, mm } \\
\hline Between group comparison & $-4.4 \pm 2.8(-9.9$ to 1.1$)$ & 0.116 \\
\hline Interaction & $-0.0 \pm 0.0(-0.0$ to 0.0$)$ & 0.744 \\
\hline \multicolumn{3}{|l|}{ Diameter stenosis, $\%$} \\
\hline Between group comparison & $-0.0 \pm 0.0(-0.1$ to 0.0$)$ & 0.061 \\
\hline Interaction & $0.0 \pm 0.0(-0.0$ to 0.0$)$ & 0.981 \\
\hline \multicolumn{3}{|l|}{ Remodeling Index } \\
\hline Between group comparison & $0.0 \pm 0.0(-0.1$ to 0.0$)$ & 0.758 \\
\hline Interaction & $-0.0 \pm 0.0(-0.0$ to 0.0$)$ & 0.121 \\
\hline \multicolumn{3}{|l|}{ Total PAV, $\%$} \\
\hline Between group comparison & $0.6 \pm 1.0(-1.4$ to 2.6$)$ & 0.551 \\
\hline Interaction & $-0.1 \pm 0.1(-0.2$ to 0.1$)$ & 0.320 \\
\hline \multicolumn{3}{|l|}{ Calcified PAV, $\%$} \\
\hline Between group comparison & $0.6 \pm 0.7(-0.8$ to 2.1$)$ & 0.391 \\
\hline Interaction & $-0.1 \pm 0.1(-0.3$ to 0.0$)$ & 0.126 \\
\hline \multicolumn{3}{|l|}{ Non-calcified PAV, \% } \\
\hline Between group comparison & $-0.6 \pm 1.0(-2.5$ to 1.2$)$ & 0.500 \\
\hline Interaction & $-0.0 \pm 0.1(-0.2$ to 0.2$)$ & 0.811 \\
\hline \multicolumn{3}{|l|}{ Fibrous PAV, $\%$} \\
\hline Between group comparison & $1.0 \pm 0.9(-0.8$ to 2.9$)$ & 0.270 \\
\hline Interaction & $-0.1 \pm 0.1(-0.3$ to 0.1$)$ & 0.559 \\
\hline \multicolumn{3}{|l|}{ Fibro-fatty PAV, $\%$} \\
\hline Between group comparison & $-1.3 \pm 0.4(-2.0$ to -0.6$)$ & $<0.001$ \\
\hline Interaction & $0.0 \pm 0.0(-0.1$ to 0.1$)$ & 0.416 \\
\hline \multicolumn{3}{|l|}{ Necrotic core PAV, $\%$} \\
\hline Between group comparison & $-0.3 \pm 0.7(-1.7$ to 1.1$)$ & 0.704 \\
\hline Interaction & $-0.0 \pm 0.1(-0.2$ to 0.2$)$ & 0.996 \\
\hline
\end{tabular}

Bold indicates statistical signifcance of $\mathrm{p}$ value $<0.05$

Values are presented as estimates $(\beta) \pm$ standard error (SE) (95\% confidence interval)

$C I$ confidence interval, $P A V$ percentage atheroma volume

\section{Clinical implications}

The higher regression of fibrous and non-calcified PAV in women compared to men younger than 55 years old is an clinically important finding. Non-calcified plaques are associated with ischemia and ACS. [28-30] The absence of this difference in the, likely post-menopausal, women of 55 years or older hints to a slowing of the regression of non-calcified PAV to match that of the men and thereby increasing the risk for symptomatic CAD. Several strategies could be considered for this increased risk. Monitoring and treatment of cardiovascular risk factors of women around the age of menopause could be employed. Coronary CTA with quantitative plaque assessment might provide additional information on risk for future symptomatic CAD which could prompt early treatment of cardiovascular risk factors. Moreover, HRT might potentially positively influence plaque compositional changes and should be investigated.

\section{Study limitations}

Similar to other trials, women were underrepresented in our study. We used 55 years as a proxy for menopause, since menopause status was unavailable from clinical records. Although, the mean age of menopause has been demonstrated to be lower than 55 years, we cannot exclude the fact that premenopausal subjects might have been included in the $\geq 55$ years age group [42]. Furthermore, information on HRT or sex hormone levels, which might have added relevant information, was also unavailable. A relative limited number of patients were included in this study and the sub analysis of sex differences in the different age groups should be interpreted with caution. As coronary CTA scanners from different vendors were used, a predefined standard operating procedure was applied to minimize variances 

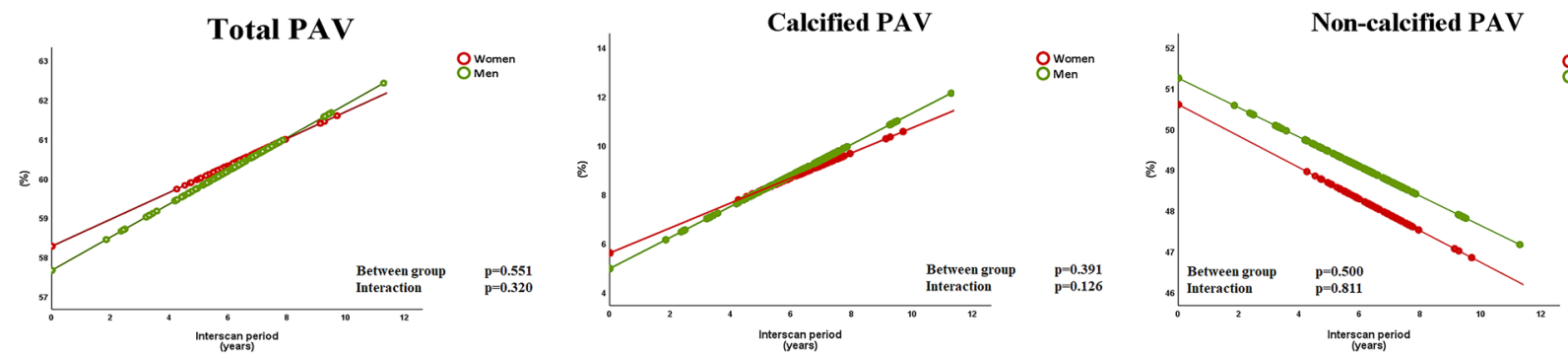

OWomen
OMen
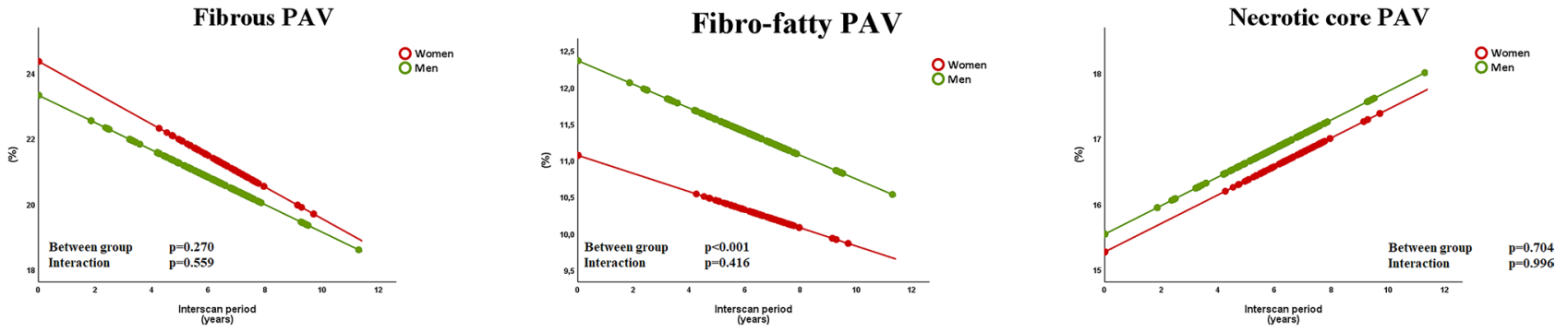

Fig. 2 Plaque changes on a per-lesion analysis shown for women and men. The line graphs represent the estimated average trend from baseline to 12 years for both groups based on a linear mixed modelling, with tests for the systematic between-group differences as well as for differences in trend. Circles represent the estimated mean percentage at the time point the follow-up scan was performed. PAV percentage atheroma volume

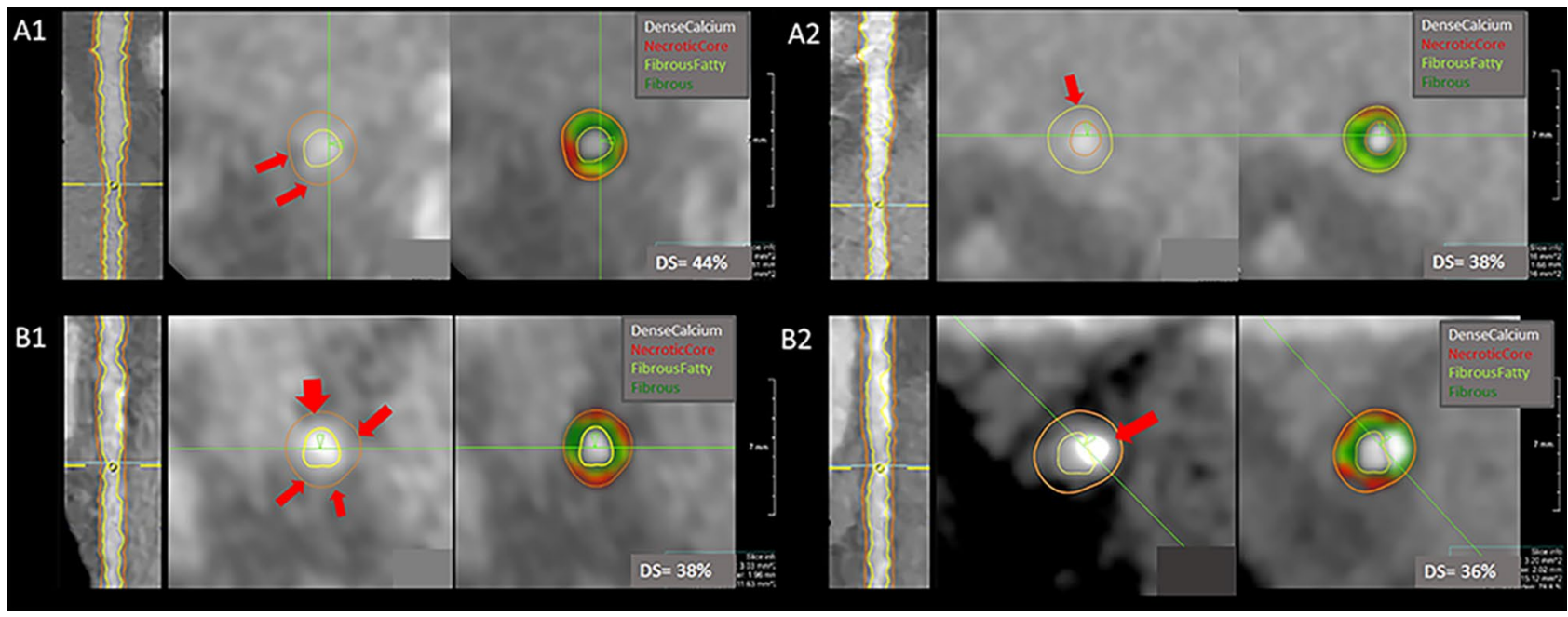

Fig. 3 Quantitative assessment of coronary plaques in a male and female patient at baseline and follow-up. Panel A represents quantitative coronary plaque analysis of a 62-year-old male patient of the mid-left anterior descending artery at baseline (A1) and after 5.4 years follow-up (A2). During follow-up reduction of necrotic core and an increase in fibrous and fibrous fatty can be observed. Panel
B represents quantitative coronary plaque analysis of a 58-year-old female patient of the proximal circumflex artery at baseline (B1) and after 5.9 years follow-up (B2). A reduction of necrotic core and the formation of dense calcium can be observed during follow-up. DS diameter stenosis 
Table 4 Plaque morphological and compositional changes on a per-lesion analysis shown for women compared to men stratified according to $<55$ or $\geq 55$ years of age

\begin{tabular}{|c|c|c|c|c|}
\hline Variables & $<55$ years $(\mathrm{n}=112) \beta \pm \mathrm{SE}(95 \% \mathrm{CI})$ & p-value & $\geq 55$ years $(\mathrm{n}=478) \beta \pm \mathrm{SE}(95 \% \mathrm{CI})$ & p-value \\
\hline \multicolumn{5}{|l|}{ Lesion length, mm } \\
\hline Between group comparison & $-9.0 \pm 9.2(-27.5$ to 9.4$)$ & 0.329 & $-4.2 \pm 2.9(-10.1$ to 1.6$)$ & 0.151 \\
\hline Interaction & $0.0 \pm 0.1(-0.1$ to 0.1$)$ & 0.871 & $-0.0 \pm 0.0(-0.1$ to 0.0$)$ & 0.580 \\
\hline \multicolumn{5}{|l|}{ Diameter stenosis, $\%$} \\
\hline Between group comparison & $-0.0 \pm 0.0(-0.1$ to 0.1$)$ & 0.659 & $-0.0 \pm 0.0(-0.1$ to 0.0$)$ & $\mathbf{0 . 0 3 1}$ \\
\hline Interaction & $0.0 \pm 0.0(-0.0$ to 0.0$)$ & 0.965 & $0.0 \pm 0.0(-0.0$ to 0.0$)$ & 0.823 \\
\hline \multicolumn{5}{|l|}{ Positive remodeling } \\
\hline Between group comparison & $-0.0 \pm 0.1(-0.1$ to 0.1$)$ & 0.649 & $0.0 \pm 0.0(-0.0$ to 0.0$)$ & 0.563 \\
\hline Interaction & $-0.0 \pm 0.0(-0.0$ to 0.0$)$ & 0.487 & $-0.0 \pm 0.0(-0.0$ to 0.0$)$ & 0.125 \\
\hline \multicolumn{5}{|l|}{ Total PAV, $\%$} \\
\hline Between group comparison & $1.5 \pm 2.9(-4.3$ to 7.3$)$ & 0.600 & $0.1 \pm 1.1(-2.1$ to 2.3$)$ & 0.919 \\
\hline Interaction & $-0.1 \pm 0.2(-0.6$ to 0.3$)$ & 0.583 & $-0.1 \pm 0.1(-0.2$ to 0.1$)$ & 0.329 \\
\hline \multicolumn{5}{|l|}{ Calcified PAV, \% } \\
\hline Between group comparison & $-0.5 \pm 1.4(-3.3$ to 2.4$)$ & 0.750 & $0.3 \pm 0.8(-1.3$ to 1.9$)$ & 0.733 \\
\hline Interaction & $-0.0 \pm 0.2(-0.4$ to 0.4$)$ & 0.987 & $-0.1 \pm 0.1(-0.3$ to 0.0$)$ & 0.130 \\
\hline \multicolumn{5}{|l|}{ Non-calcified PAV, $\%$} \\
\hline Between group comparison & $-1.3 \pm 2.6(-6.6$ to 4.0$)$ & 0.632 & $-0.5 \pm 1.0(-2.5$ to 1.6$)$ & 0.652 \\
\hline Interaction & $-0.7 \pm 0.3(-1.4$ to -0.1$)$ & 0.027 & $0.0 \pm 0.1(-0.2$ to 0.2$)$ & 0.881 \\
\hline \multicolumn{5}{|l|}{ Fibrous PAV, \% } \\
\hline Between group comparison & $0.1 \pm 2.8(-5.4$ to 5.7$)$ & 0.968 & $0.7 \pm 1.0(-1.2$ to 2.7$)$ & 0.449 \\
\hline Interaction & $-0.8 \pm 0.3(-1.3$ to -0.3$)$ & 0.002 & $0.0 \pm 0.1(-0.2$ to 0.2$)$ & 0.923 \\
\hline \multicolumn{5}{|l|}{ Fibro-fatty PAV, $\%$} \\
\hline Between group comparison & $-2.4 \pm 1.0(-4.4$ to -0.4$)$ & 0.020 & $-1.0 \pm 0.4(-1.8$ to -0.3$)$ & 0.010 \\
\hline Interaction & $-0.1 \pm 0.2(-0.4$ to 0.2$)$ & 0.676 & $0.0 \pm 0.0(-0.1$ to 0.1$)$ & 0.476 \\
\hline \multicolumn{5}{|l|}{ Necrotic core PAV, $\%$} \\
\hline Between group comparison & $0.7 \pm 2.0(-3.3$ to 4.8$)$ & 0.725 & $-0.0 \pm 0.8(-1.5$ to 1.4$)$ & 0.965 \\
\hline Interaction & $0.1 \pm 0.2(-0.3$ to 0.6$)$ & 0.590 & $-0.0 \pm 0.1(-0.2$ to 0.2$)$ & 0.744 \\
\hline
\end{tabular}

Bold indicates statistical signifcance of $\mathrm{p}$ value $<0.05$

Values are presented as estimates $(\beta) \pm$ standard error (SE) (95\% confidence interval)

$C I$ confidence interval, $P A V$ percentage atheroma volume 

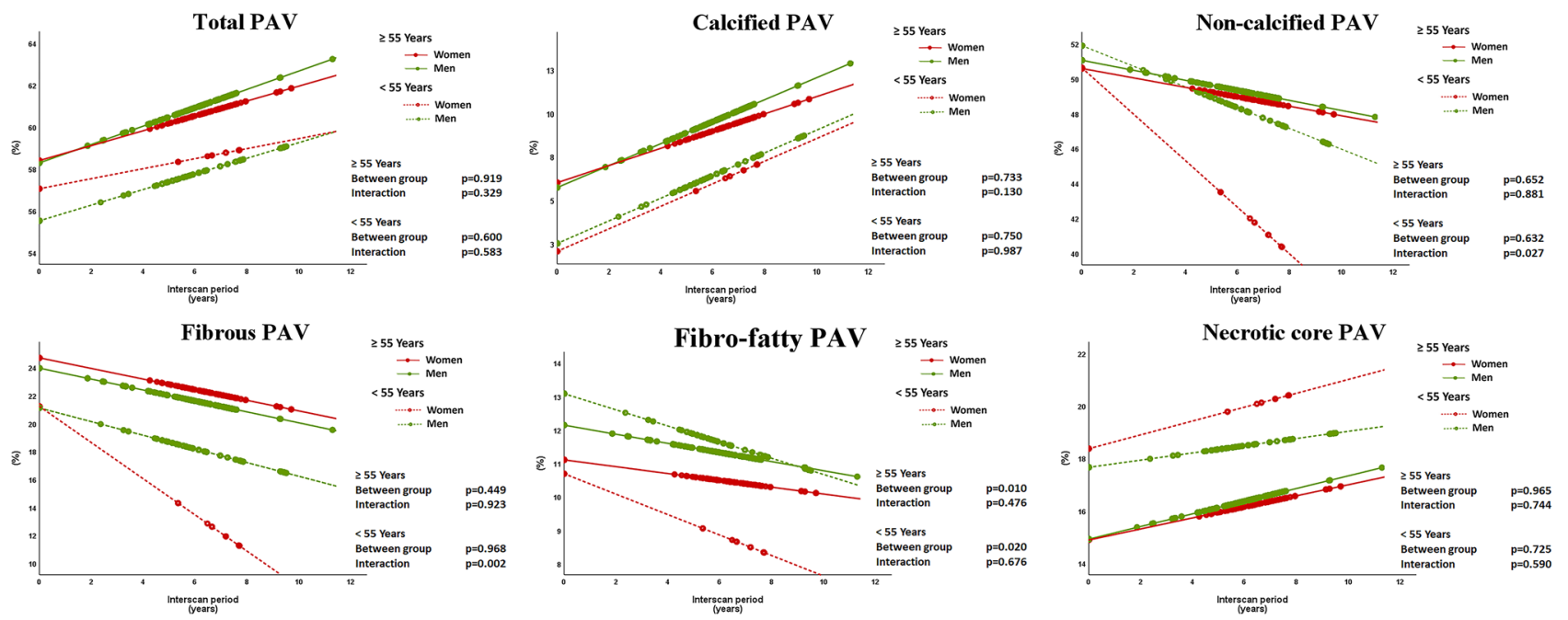

Fig. 4 Plaque changes on a per-lesion analysis shown for women and men stratified according to the age group ( $<55$ vs $\geq 55$ years old). The line graphs represent the estimated average trend from baseline to 12 years for both groups based on a linear mixed modelling, with tests for the systematic between-group differences as well as for differences in trend. Circles represent the estimated mean percentage at the time point the follow-up scan was performed. $P A V$ percentage atheroma volume among centers and quantitative analysis was performed in the core lab exclusively on visually recognized plaques: however, although careful visual examination was performed in the whole coronary tree, some plaques might have been unrecognized.

\section{Conclusions}

In a low-to-intermediate risk population of stable CAD with serial CTA scan during a follow-up of $6.2 \pm 1.4$ years women younger than 55 years demonstrated, after correction for several cardiovascular risk factors, a more pronounced reduction of fibrous and non-calcified PAV compared to age-matched men. No differences in the change of total or compositional PAV were observed between women and men of 55 years or older. Finally, the absolute value of fibro-fatty PAV was consistently higher in men than in women at any age.

Supplementary Information The online version contains supplementary material available at https://doi.org/10.1007/s10554-021-02204-4.

Acknowledgements We would like to thank all SMARTool Clinical Investigators who made possible patient enrollment and availability of clinical data, CTCAs and blood samples.

Funding This work is partially funded by the European Commission: Project SMARTool, "Simulation Modeling of coronary ARTery disease: a tool for clinical decision support - SMARTool" [GA number: 689068].

\section{Declarations}

Conflict of interest The department of Cardiology of Leiden University Medical Center received unrestricted research grants from Abbott Vascular, Bayer, Bioventrix, Biotronik, Boston Scientific, Edwards Lifesciences, GE Healthcare and Medtronic. The University Hospital Zurich holds a research agreement with GE Healthcare. Ronny R. Buechel reports receiving speaker honoraria from GE Healthcare. J. Knuuti discloses speaker fees from GE Healthcare, Merck, Lundbeck and Bayer and study protocol consultancy fees from GE Healthcare and AstraZeneca outside of submitted work.

Ethical approval The study protocol was submitted to the Ethics Committe CEAVNO, Comitato Etico Sperimentazione Clinica Area Vasta Nord-Ovest (Pisa, Italy) and approved by letter. n. 23534 of 14/04/2016. The study protocol was approved by all local ethical committees and all patients gave their written informed consent to participate in the study. (ClinicalTrials.gov number, NCT04448691.)

Open Access This article is licensed under a Creative Commons Attribution 4.0 International License, which permits use, sharing, adaptation, distribution and reproduction in any medium or format, as long as you give appropriate credit to the original author(s) and the source, provide a link to the Creative Commons licence, and indicate if changes were made. The images or other third party material in this article are included in the article's Creative Commons licence, unless indicated otherwise in a credit line to the material. If material is not included in the article's Creative Commons licence and your intended use is not permitted by statutory regulation or exceeds the permitted use, you will need to obtain permission directly from the copyright holder. To view a copy of this licence, visit http://creativecommons.org/licenses/by/4.0/. 


\section{References}

1. Anand SS, Islam S, Rosengren A, Franzosi MG, Steyn K, Yusufali AH, Keltai M, Diaz R, Rangarajan S, Yusuf S, Investigators obotI, (2008) Risk factors for myocardial infarction in women and men: insights from the INTERHEART study. Eur Heart J 29(7):932-940. https://doi.org/10.1093/eurheartj/ehn018

2. Shaw LJ, Bairey Merz CN, Pepine CJ, Reis SE, Bittner V, Kelsey SF, Olson M, Johnson BD, Mankad S, Sharaf BL, Rogers WJ, Wessel TR, Arant CB, Pohost GM, Lerman A, Quyyumi AA, Sopko G (2006) Insights from the NHLBI-Sponsored Women's Ischemia Syndrome Evaluation (WISE) Study: Part I: gender differences in traditional and novel risk factors, symptom evaluation, and gender-optimized diagnostic strategies. J Am Coll Cardiol 47(3 Suppl):S4-s20. https://doi.org/10.1016/j.jacc.2005.01.072

3. Sedlak TL, Lee M, Izadnegahdar M, Merz CN, Gao M, Humphries KH (2013) Sex differences in clinical outcomes in patients with stable angina and no obstructive coronary artery disease. Am Heart J 166(1):38-44. https://doi.org/10.1016/j.ahj.2013.03.015

4. Vaccarino V, Parsons L, Every NR, Barron HV, Krumholz HM (1999) Sex-based differences in early mortality after myocardial infarction. National Registry of Myocardial Infarction 2 Participants. N Engl J Med 341(4):217-225. https://doi.org/10.1056/ nejm199907223410401

5. Lawesson SS, Stenestrand U, Lagerqvist B, Wallentin L, Swahn E (2010) Gender perspective on risk factors, coronary lesions and long-term outcome in young patients with ST-elevation myocardial infarction. Heart 96(6):453-459. https://doi. org/10.1136/hrt.2009.175463

6. Virmani R, Burke AP, Farb A, Kolodgie FD (2006) Pathology of the vulnerable plaque. J Am Coll Cardiol 47(8 Suppl):C13-18. https://doi.org/10.1016/j.jacc.2005.10.065

7. Dollar AL, Kragel AH, Fernicola DJ, Waclawiw MA, Roberts WC (1991) Composition of atherosclerotic plaques in coronary arteries in women less than 40 years of age with fatal coronary artery disease and implications for plaque reversibility. Am J Cardiol 67(15):1223-1227. https://doi.org/10.1016/00029149(91)90931-a

8. Mautner SL, Lin F, Mautner GC, Roberts WC (1993) Comparison in women versus men of composition of atherosclerotic plaques in native coronary arteries and in saphenous veins used as aortocoronary conduits. J Am Coll Cardiol 21(6):1312-1318. https://doi.org/10.1016/0735-1097(93)90302-h

9. Farb A, Burke AP, Tang AL, Liang Y, Mannan P, Smialek J, Virmani R (1996) Coronary Plaque Erosion Without Rupture Into a Lipid Core. Circulation 93(7):1354-1363. https://doi. org/10.1161/01.CIR.93.7.1354

10. Burke AP, Farb A, Malcom GT, Liang Y-h, Smialek J, Virmani R (1998) Effect of risk factors on the mechanism of acute thrombosis and sudden coronary death in women. Circulation 97(21):2110-2116. https://doi.org/10.1161/01.CIR.97.21.2110

11. Kornowski R, Lansky AJ, Mintz GS, Kent KM, Pichard AD, Satler LF, Bucher TA, Popma JJ, Leon MB (1997) Comparison of men versus women in cross-sectional area luminal narrowing, quantity of plaque, presence of calcium in plaque, and lumen location in coronary arteries by intravascular ultrasound in patients with stable angina pectoris. Am J Cardiol 79(12):1601-1605. https://doi.org/10.1016/s0002-9149(97)00206-3

12. Nicholls SJ, Wolski K, Sipahi I, Schoenhagen P, Crowe T, Kapadia SR, Hazen SL, Tuzcu EM, Nissen SE (2007) Rate of progression of coronary atherosclerotic plaque in women. J Am Coll Cardiol 49(14):1546-1551. https://doi.org/10.1016/j.jacc.2006.12.039

13. Qian J, Maehara A, Mintz GS, Margolis MP, Lerman A, Rogers J, Banai S, Kazziha S, Castellanos C, Dani L, Fahy M, Stone GW, Leon MB (2009) Impact of gender and age on in vivo virtual histology-intravascular ultrasound imaging plaque characterization (from the global Virtual Histology Intravascular Ultrasound [VH-IVUS] registry). Am J Cardiol 103(9):1210-1214. https:// doi.org/10.1016/j.amjcard.2009.01.031

14. Hong YJ, Jeong MH, Choi YH, Ma EH, Cho SH, Ko JS, Lee MG, Park KH, Sim DS, Yoon NS, Youn HJ, Kim KH, Park HW, Kim JH, Ahn Y, Cho JG, Park JC, Kang JC (2010) Gender differences in coronary plaque components in patients with acute coronary syndrome: virtual histology-intravascular ultrasound analysis. J Cardiol 56(2):211-219. https://doi.org/10.1016/j.jjcc.2010.05.009

15. Lansky AJ, Ng VG, Maehara A, Weisz G, Lerman A, Mintz GS, De Bruyne B, Farhat N, Niess G, Jankovic I, Lazar D, Xu K, Fahy M, Serruys PW, Stone GW (2012) Gender and the extent of coronary atherosclerosis, plaque composition, and clinical outcomes in acute coronary syndromes. J Am Coll Cardiol Img 5(3 Suppl):S62-72. https://doi.org/10.1016/j.jcmg.2012.02.003

16. Stegman B, Shao M, Nicholls SJ, Elshazly M, Cho L, King P, Kapadia S, Tuzcu M, Nissen SE, Puri R (2016) Coronary atheroma progression rates in men and women following highintensity statin therapy: A pooled analysis of REVERSAL, ASTEROID and SATURN. Atherosclerosis 254:78-84. https ://doi.org/10.1016/j.atherosclerosis.2016.09.059

17. Ten Haaf ME, Rijndertse M, Cheng JM, de Boer SP, GarciaGarcia HM, van Geuns RM, Regar E, Lenzen MJ, Appelman Y, Boersma E (2017) Sex differences in plaque characteristics by intravascular imaging in patients with coronary artery disease. EuroIntervention 13(3):320-328. https://doi.org/10.4244/ eij-d-16-00361

18. Chia S, Christopher Raffel O, Takano M, Tearney GJ, Bouma BE, Jang IK (2007) In-vivo comparison of coronary plaque characteristics using optical coherence tomography in women vs men with acute coronary syndrome. Coron Artery Dis 18(6):423-427. https://doi.org/10.1097/MCA.0b013e3282 583 be 8

19. Guagliumi G, Capodanno D, Saia F, Musumeci G, Tarantini G, Garbo R, Tumminello G, Sirbu V, Coccato M, Fineschi M, Trani C, De Benedictis M, Limbruno U, De Luca L, Niccoli G, Bezerra H, Ladich E, Costa M, Biondi Zoccai G, Virmani R (2014) Mechanisms of atherothrombosis and vascular response to primary percutaneous coronary intervention in women versus men with acute myocardial infarction: results of the OCTAVIA study. J Am Coll Cardiol Interv 7(9):958-968. https://doi. org/10.1016/j.jcin.2014.05.011

20. Kataoka Y, Puri R, Hammadah M, Duggal B, Uno K, Kapadia SR, Tuzcu EM, Nissen SE, King P, Nicholls SJ (2016) Sex Differences in Nonculprit Coronary Plaque Microstructures on FrequencyDomain Optical Coherence Tomography in Acute Coronary Syndromes and Stable Coronary Artery Disease. Circ Cardiovasc Imaging. https://doi.org/10.1161/circimaging.116.004506

21. Mariani L, Burzotta F, Aurigemma C, Romano A, Niccoli G, Leone AM, Porto I, Trani C, Crea F (2017) Frequency-domain optical coherence tomography plaque morphology in stable coronary artery disease: sex differences. Coron Artery Dis 28(6):472477. https://doi.org/10.1097/mca.0000000000000522

22. Tian J, Wang X, Tian J, Yu B (2019) Gender differences in plaque characteristics of nonculprit lesions in patients with coronary artery disease. BMC Cardiovasc Disord 19(1):45. https://doi. org/10.1186/s12872-019-1023-5

23. de Graaf MA, Broersen A, Kitslaar PH, Roos CJ, Dijkstra J, Lelieveldt BP, Jukema JW, Schalij MJ, Delgado V, Bax JJ, Reiber JH, Scholte AJ (2013) Automatic quantification and characterization of coronary atherosclerosis with computed tomography coronary angiography: cross-correlation with intravascular ultrasound virtual histology. Int J Cardiovasc Imaging 29(5):1177-1190. https://doi.org/10.1007/s10554-013-0194-x 
24. Sakellarios A, Siogkas P, Georga E, Tachos N, Kigka V, Tsompou P, Andrikos I, Karanasiou GS, Rocchiccioli S, Correia J, Pelosi G, Stofella P, Filipovic N, Parodi O, Fotiadis DI (2018) A clinical decision support platform for the risk stratification, diagnosis, and prediction of coronary artery disease evolution. Conf Proc IEEE Eng Med Biol Soc 2018:4556-4559. https://doi.org/10.1109/ embc.2018.8513131

25. Smit JM, van Rosendael AR, El Mahdiui M, Neglia D, Knuuti J, Saraste A, Buechel RR, Teresinska A, Pizzi MN, Roque A, Poddighe R, Mertens BJ, Caselli C, Rocchiccioli S, Parodi O, Pelosi G, Scholte AJ (2020) Impact of clinical characteristics and statins on coronary plaque progression by serial computed tomography angiography. Circ Cardiovasc Imaging 13(3):e009750. https://doi. org/10.1161/circimaging. 119.009750

26. Diamond GA, Forrester JS (1979) Analysis of probability as an aid in the clinical diagnosis of coronary-artery disease. N Engl J Med 300(24):1350-1358. https://doi.org/10.1056/nejm197906 143002402

27. Grundy SM, Stone NJ, Bailey AL, Beam C, Birtcher KK, Blumenthal RS, Braun LT, de Ferranti S, Faiella-Tommasino J, Forman DE, Goldberg R, Heidenreich PA, Hlatky MA, Jones DW, LloydJones D, Lopez-Pajares N, Ndumele CE, Orringer CE, Peralta CA, Saseen JJ, Smith SC Jr, Sperling L, Virani SS, Yeboah J (2019) 2018 AHA/ACC/AACVPR/AAPA/ABC/ACPM/ADA/ AGS/APhA/ASPC/NLA/PCNA guideline on the management of blood cholesterol: executive summary: a report of the American college of cardiology/American heart association task force on clinical practice guidelines. Circulation 139(25):e1046-e1081. https://doi.org/10.1161/cir.0000000000000624

28. Boogers MJ, Broersen A, van Velzen JE, de Graaf FR, El-Naggar HM, Kitslaar PH, Dijkstra J, Delgado V, Boersma E, de Roos A, Schuijf JD, Schalij MJ, Reiber JHC, Bax JJ, Jukema JW (2012) Automated quantification of coronary plaque with computed tomography: comparison with intravascular ultrasound using a dedicated registration algorithm for fusion-based quantification. Eur Heart J 33(8):1007-1016. https://doi.org/10.1093/eurheartj/ ehr465

29. Budoff MJ, Ellenberg SS, Lewis CE, Mohler ER 3rd, Wenger NK, Bhasin S, Barrett-Connor E, Swerdloff RS, Stephens-Shields A, Cauley JA, Crandall JP, Cunningham GR, Ensrud KE, Gill TM, Matsumoto AM, Molitch ME, Nakanishi R, Nezarat N, Matsumoto S, Hou X, Basaria S, Diem SJ, Wang C, Cifelli D, Snyder PJ (2017) Testosterone treatment and coronary artery plaque volume in older men with low testosterone. JAMA 317(7):708-716. https ://doi.org/10.1001/jama.2016.21043

30. de Knegt MC, Haugen M, Linde JJ, Kühl JT, Nordestgaard BG, Køber LV, Hove JD, Kofoed KF (2018) Reproducibility of quantitative coronary computed tomography angiography in asymptomatic individuals and patients with acute chest pain. PLoS ONE 13(12):e0207980. https://doi.org/10.1371/journal.pone.0207980

31. Bharadwaj AS, Vengrenyuk Y, Yoshimura T, Baber U, Hasan C, Narula J, Sharma SK, Kini AS (2016) Multimodality intravascular imaging to evaluate sex differences in plaque morphology in stable CAD. J Am Coll Cardiol Img 9(4):400-407. https://doi. org/10.1016/j.jcmg.2016.02.007

32. Versteylen MO, Kietselaer BL, Dagnelie PC, Joosen IA, Dedic A, Raaijmakers RH, Wildberger JE, Nieman K, Crijns HJ, Niessen WJ, Daemen MJ, Hofstra L (2013) Additive value of semiautomated quantification of coronary artery disease using cardiac computed tomographic angiography to predict future acute coronary syndrome. J Am Coll Cardiol 61(22):2296-2305. https://doi. org/10.1016/j.jacc.2013.02.065

33. Driessen RS, Stuijfzand WJ, Raijmakers PG, Danad I, Min JK, Leipsic JA, Ahmadi A, Narula J, van de Ven PM, Huisman MC, Lammertsma AA, van Rossum AC, van Royen N, Knaapen P (2018) Effect of plaque burden and morphology on myocardial blood flow and fractional flow reserve. J Am Coll Cardiol 71(5):499-509. https://doi.org/10.1016/j.jacc.2017.11.054

34. Chang HJ, Lin FY, Lee SE, Andreini D, Bax J, Cademartiri F, Chinnaiyan K, Chow BJW, Conte E, Cury RC, Feuchtner G, Hadamitzky M, Kim YJ, Leipsic J, Maffei E, Marques H, Plank F, Pontone G, Raff GL, van Rosendael AR, Villines TC, Weirich HG, Al'Aref SJ, Baskaran L, Cho I, Danad I, Han D, Heo R, Lee JH, Rivzi A, Stuijfzand WJ, Gransar H, Lu Y, Sung JM, Park HB, Berman DS, Budoff MJ, Samady H, Shaw LJ, Stone PH, Virmani R, Narula J, Min JK (2018) Coronary Atherosclerotic Precursors of Acute Coronary Syndromes. J Am Coll Cardiol 71(22):25112522. https://doi.org/10.1016/j.jacc.2018.02.079

35. Mendelsohn ME, Karas RH (2005) Molecular and cellular basis of cardiovascular gender differences. Science 308(5728):1583-1587. https://doi.org/10.1126/science.1112062

36. Rossouw JE, Anderson GL, Prentice RL, LaCroix AZ, Kooperberg C, Stefanick ML, Jackson RD, Beresford SA, Howard BV, Johnson KC, Kotchen JM, Ockene J (2002) Risks and benefits of estrogen plus progestin in healthy postmenopausal women: principal results From the Women's Health Initiative randomized controlled trial. JAMA 288(3):321-333. https://doi.org/10.1001/ jama.288.3.321

37. Anderson GL, Limacher M, Assaf AR, Bassford T, Beresford SA, Black H, Bonds D, Brunner R, Brzyski R, Caan B, Chlebowski R, Curb D, Gass M, Hays J, Heiss G, Hendrix S, Howard BV, Hsia J, Hubbell A, Jackson R, Johnson KC, Judd H, Kotchen JM, Kuller L, LaCroix AZ, Lane D, Langer RD, Lasser N, Lewis CE, Manson J, Margolis K, Ockene J, O’Sullivan MJ, Phillips L, Prentice RL, Ritenbaugh C, Robbins J, Rossouw JE, Sarto G, Stefanick ML, Van Horn L, Wactawski-Wende J, Wallace R, Wassertheil-Smoller $S$ (2004) Effects of conjugated equine estrogen in postmenopausal women with hysterectomy: the Women's Health Initiative randomized controlled trial. JAMA 291(14):1701-1712. https://doi. org/10.1001/jama.291.14.1701

38. Hodis HN, Mack WJ, Henderson VW, Shoupe D, Budoff MJ, Hwang-Levine J, Li Y, Feng M, Dustin L, Kono N, Stanczyk FZ, Selzer RH, Azen SP (2016) Vascular Effects of Early versus Late Postmenopausal Treatment with Estradiol. N Engl J Med 374(13):1221-1231. https://doi.org/10.1056/NEJMoa1505241

39. Herrington DM, Reboussin DM, Brosnihan KB, Sharp PC, Shumaker SA, Snyder TE, Furberg CD, Kowalchuk GJ, Stuckey TD, Rogers WJ, Givens DH, Waters D (2000) Effects of estrogen replacement on the progression of coronary-artery atherosclerosis. N Engl J Med 343(8):522-529. https://doi.org/10.1056/nejm2 00008243430801

40. Hodis HN, Mack WJ, Lobo RA, Shoupe D, Sevanian A, Mahrer PR, Selzer RH, Liu Cr CR, Liu Ch CH, Azen SP (2001) Estrogen in the prevention of atherosclerosis. A randomized, double-blind, placebo-controlled trial. Ann Intern Med 135(11):939-953. https ://doi.org/10.7326/0003-4819-135-11-200112040-00005

41. Hodis HN, Mack WJ, Azen SP, Lobo RA, Shoupe D, Mahrer PR, Faxon DP, Cashin-Hemphill L, Sanmarco ME, French WJ, Shook TL, Gaarder TD, Mehra AO, Rabbani R, Sevanian A, Shil AB, Torres M, Vogelbach KH, Selzer RH (2003) Hormone therapy and the progression of coronary-artery atherosclerosis in postmenopausal women. N Engl J Med 349(6):535-545. https://doi. org/10.1056/NEJMoa030830

42. InterLACE Study Team (2019) Variations in reproductive events across life: a pooled analysis of data from 505147 women across 10 countries. Hum Reprod 34(5):881-893. https://doi. org/10.1093/humrep/dez015

Publisher's Note Springer Nature remains neutral with regard to jurisdictional claims in published maps and institutional affiliations. 